\title{
IMPACTOS DO ISOLAMENTO CONJUGAL SOBRE A ROTINA DA MULHER DO EMIGRADO
}

\author{
Clarisse Sousa Boechat \\ Carlos Alberto Dias" \\ Emilliane de Oliveira Matos" \\ Agnes Rocha de Almeida \\ Adilson Rodrigues Coelho ${ }^{\Phi}$
}

\begin{abstract}
RESUMO. Segundo a literatura, o isolamento social tende a favorecer o surgimento de problemas relacionados à saúde física e emocional, independentemente de gênero, idade e estado civil. O presente estudo procura conhecer as implicações do processo emigratório sobre o cotidiano de mulheres residentes em Governador Valadares - MG cujos parceiros se encontram no exterior como imigrantes. Trata-se de uma pesquisa exploratória na qual realizadas 247 entrevistas domiciliares com mulheres residentes na cidade de Governador Valadares cujos parceiros residem no exterior na condição de imigrantes há pelo menos três meses. Os dados revelaram que a partir deste isolamento as mulheres tornaram-se menos sociáveis, deixaram de participar de atividades usuais de lazer e distanciaram-se de amigos, enfraquecendo sua rede de apoio social. $\mathrm{O}$ isolamento conjugal, além de provocar significativas mudanças na rotina da mulher, produz mudanças em sua autopercepção e no modo de avaliação de seu relacionamento conjugal.
\end{abstract}

Palavras-chave: Emigração; mulheres de emigrantes; isolamento conjugal.

\section{IMPACTS OF CONJUGAL ISOLATION ON THE ROUTINE OF THE EMIGRANT'S WIFE}

\begin{abstract}
According to the literature, social isolation tends to favor the worsening of the physical and emotional health, regardless gender, age and marital status. This study searches to take knowledge of the migratory process implications on the women's daily life, resident in Governador Valadares, who have their partners abroad as emigrants. It is an exploratory research, having been made 247 home interviews with resident women in Governador Valadares, whose partners live abroad as emigrants for a minimal period of three months. The data reveal that with this isolation women have become less sociable, stopped participating in common leisure activities, and set apart of friends, weakening their social support and net. The conjugal isolation, besides provoking significant changes in the woman's routine, produces changes in their self-perception and in the way of evaluation of their conjugal relationship.
\end{abstract}

Key words: Emigration ; emigrants' wives ; conjugal isolation.

\section{LOS IMPACTOS DEL MATRIMONIO EN EL AISLAMIENTO DE RUTINA DE LA MUJER DEL INMIGRADO}

RESUMEN. Según la literatura, el aislamiento social tiende a favorecer el surgimiento de problemas relacionados a la salud física y emocional, independientemente del género, edad y estado civil. El presente estudio busca conocer las implicaciones del proceso emigratorio sobre el cotidiano de mujeres residentes en Governador Valadares - MG cuyos parceros se encuentran en el exterior como inmigrantes. Se trata de una pesquisa exploratoria en la cual realizadas 247 entrevistas domiciliares con mujeres residentes en la ciudad de Governador Valadares cuyos parceros residen en el exterior en la condición de inmigrantes hace por lo menos tres meses. Los datos revelaron que a partir de este aislamiento las mujeres se conviertieron en menos

\footnotetext{
Graduanda do curso de Psicologia da Universidade Vale do Rio Doce (UNIVALE). Bolsista de Iniciação Científica pela Fundação de Amparo à pesquisa do Minas Gerais - FAPEMIG.

\# Doutor em Psicologia Clínica pela Universidade de Amiens. Professor adjunto da Universidade Vale do Rio Doce.

If Graduanda do curso de Psicologia da Universidade Vale do Rio Doce (UNIVALE). Bolsista de Iniciação Científica pela Fundação de Amparo à pesquisa do Minas Gerais - FAPEMIG.

x Psicologa, Pos-graduada em Dependência Quimica e Outros Transtornos Compulsivos e pós-graduada em Gestão de Território e do Patrimônio Cultural pela mesma Universidade. Professora de cursos relacionados à disciplina Psicologia organizacional nos cursos de Administração de Empresas e Gestao de Recursos Humanos.

$\Phi \quad$ Mestre em Filosofia pela Universidade Federal de Minas Gerais (1992) . Professor Adjunto I do Fundação Percival Farquhar.
} 
sociables, dejaron de participar de actividades usuales de lazer y se distanciaron de amigos, enfraqueciendo su red de apoyo social. El aislamiento conjugal, además de provocar significativas mudanzas en la rutina de la mujer, produce mudanzas en su autopercepción y en el modo de evaluación de su relacionamiento conjugal.

Palabras-clave: Emigración; mujeres de emigrantes; aislamiento conjugal.

\section{UM CONTEXTO EMIGRATÓRIO}

Localizada no Leste do Estado de Minas Gerais, a 303 quilômetros de Belo Horizonte, Governador Valadares adquiriu notoriedade nacional em decorrência de sua cultura emigratória. Embora o processo emigratório na cidade tenha iniciado entre as décadas de 1950 (Assis, 2002) e 1960 (Siqueira, 2004), a emigração maciça teve seu apogeu no final da década de 1980, quando milhares de cidadãos partiram (como ainda partem) para o Exterior, especialmente para os Estados Unidos.

Segundo Assis (2002), tornar-se emigrante é um projeto econômico, familiar e afetivo. A esse título, Fusco (2006) relata que $40 \%$ dos valadarenses que emigram para os Estados Unidos contam com o apoio financeiro familiar para realizar a viagem. Um dos principais objetivos dos envolvidos é conseguir a quantia desejada de dinheiro no exterior, retornar à cidade de origem e realizar projetos familiares até então impossíveis por dificuldades de ordem econômica.

Com base em seus estudos, Assis (2007) estimou que $6,7 \%$ dos valadarenses vivem ou já viveram por algum tempo no Exterior como imigrantes. Considerando-se a atual população do município, que é de 260.396 habitantes (IBGE, 2007), pode-se estimar que o número dos cidadãos implicados no processo seja da ordem de 17.446. Vale ressaltar que uma estimativa mais precisa do número de valadarenses que partiram para o exterior é dificultada pelo fato de a grande maioria partir de forma ilegal ou não documentada. Quanto às diversas formas utilizadas pelos valadarenses para tornar-se parte do processo, as quais, por sua vez, ofuscam a possibilidade de estatísticas mais precisas, Fusco (2001, p. 1) fez o seguinte comentário: "O fluxo valadarense é um movimento recente e ainda em fase de ajustes em sua configuração".

A impossibilidade de estatísticas fidedignas cria diversas previsões que se distanciam daquela de Assis. A título de exemplo, Machado e Reis (2007) assinalam que a prefeitura de Governados Valadares estima que cerca de 40.000 valadarenses se encontrem nos EUA como imigrantes. O fator econômico foi e continua sendo preponderante na decisão de emigrar. Conseguir trabalho no Exterior, pagar dívidas contraídas, adquirir casa própria ou melhorar a situação financeira são algumas das variáveis propulsoras desse movimento. O fato de viver nos EUA longe da família e trabalhar por mais de doze horas diárias em subempregos não constitui empecilho para a ida, uma vez que a remuneração em dólares (moeda mais valorizada que o real) arrefece os aspectos negativos. Trabalhar nos EUA significa, muitas vezes, a realização de projetos que seriam inviáveis antes as adversidades financeiras vivenciadas no município de Governador Valadares.

De acordo com Almeida e Dias (2004), a maioria das mulheres de emigrantes, apesar do receio inicial quanto à separação física do casal, tende, diante das dificuldades econômicas vivenciadas, a incentivá-los a tentar a sorte em outro país. A princípio, predomina o temor relativo à distância, à fidelidade conjugal e a uma possível separação proveniente da nova situação relacional do casal; contudo, em geral, os aspectos econômicos acabam sendo priorizados em detrimento da estabilidade emocional.

$\mathrm{O}$ apoio oferecido pelas mulheres que permanecem na cidade não é isento de prejuízos familiares, emocionais, psicológicos e de arrependimento quanto à conivência com a partida do parceiro. Os prejuízos mais significativos sedimentamse com o tempo de distanciamento, sendo difícil uma avaliação prévia das consequências dessa ruptura familiar.

Este artigo lança um olhar sobre as circunstâncias experimentadas por mulheres de emigrados valadarenses que permanecem por anos a fio na cidade administrando remessas de dinheiro enviadas, cuidando da casa, da educação dos filhos e assumindo compromissos que na configuração anterior à ida do parceiro não seriam assumidos. Outra alteração significativa que se delineia no seio dessa condição de espera é o isolamento social gradativamente vivenciado por essas mulheres. Os fatores que geram tal isolamento e as consequências por ele produzidas serão o foco da presente discussão. É em decorrência dessa realidade que o presente estudo tem por objetivo conhecer as implicações do processo emigratório sobre o cotidiano de mulheres residentes em Governador Valadares cujos parceiros se encontram no Exterior como imigrantes. 
Vale especificar que termos recorrentes no artigo, como rede social e o apoio social, não são sinônimos, apesar de estarem relacionados. Por rede social entende-se o grupo de pessoas com as quais o indivíduo mantém contato ou alguma forma de vínculo social (Bowling, 1997). O apoio social, por sua vez, diz respeito à ordem de grandeza operacional ou qualitativa da rede social. Assim, o apoio social considera a disponibilidade de pessoas com quem se pode contar em situações difíceis para receber, por exemplo, auxílio emocional, afetivo ou material, como também a sentir-se parte valorizada no contexto dos grupos dos quais faz parte (Norbeck, Lindsey \& Carrieri, 1981).

Por fim, vale salientar que o processo emigratório não é um fenômeno ocasional, mas um elemento constitutivo da identidade social valadarense. Embora seja visto como uma possibilidade de melhoria da qualidade de vida de inúmeras famílias, o emigrar, mais do que uma esperança, é uma denúncia. Quanto maior o número daqueles que partem, ou desejam fazê-lo, maior é a prova de que não se estão criando recursos para manter na cidade, região, estado e país, inúmeros profissionais qualificados, obrigando-os a aventurar-se a exercer subempregos em outros países.

\section{MÉTODO}

O presente artigo é resultado de uma pesquisa descritiva do tipo exploratório, na qual foram utilizadas tanto a abordagem quantitativa quanto a qualitativa. A combinação das duas abordagens pode produzir resultados de melhor qualidade sem esforços excessivos adicionais e ser um meio eficiente de aumentar a compreensão do objeto de estudo.

O universo de estudo foi constituído de mulheres casadas ou que possuíam algum vínculo conjugal e residiam na cidade de Governador Valadares e cujos parceiros estavam residindo no Exterior como imigrantes havia pelo menos três meses. Para a composição do grupo de participantes utilizou-se a amostragem intencional (amostra não probabilística), considerando-se que muitos membros do subconjunto a ser estudado são facilmente identificados, embora sua enumeração total se revele quase impossível. $\mathrm{Na}$ situação da pesquisa considerou-se importante que a investigação contemplasse mulheres que, além de assumir as tarefas de gestão, acompanhassem o desenvolvimento dos filhos no lar e nas escolas. $\mathrm{O}$ contato com as escolas situadas na cidade constituiuse num recurso incontornável para o cadastramento das participantes. Define-se amostragem intencional como uma amostra baseada no "próprio conhecimento da população e dos seus elementos, e da natureza das metas de pesquisa" (Babbie, 2005, p. 153).

No grupo amostral foram incluídas mulheres que tinham na época ou que já haviam tido o parceiro residindo no Exterior por um período mínimo de três meses, bem como mulheres cujo parceiro havia tido sucessivos períodos de permanência no Exterior com durabilidade média de um ano. Foram excluídas mulheres que, apesar de indicadas, sentiram-se profundamente angustiadas diante da questão em estudo, bem como aquelas que se recusaram a participar da pesquisa após terem sido informadas de seus objetivos.

Para testar o método de trabalho, os processos técnicos envolvidos na execução do projeto e os instrumentos utilizados pela coleta de dados, foi realizado um estudo piloto com 20 mulheres, utilizando-se os critérios de inclusão e exclusão; porém os dados fornecidos por elas não foram considerados no estudo principal. O Estudo piloto permitiu avaliar a clareza e objetividade da entrevista.

Para a coleta dos dados foram cumpridas as etapas descritas a seguir.

1. Inicialmente foram mantidos contatos com as diretoras de escolas das redes pública e privada de Governador Valadares e discutida a possibilidade de realização da palestra "Dicas para a educação dos filhos que possuem o pai no exterior" para as mães de alunos cujo parceiro fosse emigrante.

2. Após a autorização da direção da escola, foi agendado o dia do encontro por meio de um convite formal às mães em questão, para participarem do evento.

3. Ao final da palestra, cuja duração era em torno de 60 minutos, fez-se uma apresentação da pesquisa e convite para participação. De acordo com o interesse das mulheres foi possível a criação de um cadastro com identificação e telefone de mães que estivessem dispostas a fazer parte da pesquisa.

4. A partir do cadastro, procedeu-se ao contato telefônico e ao agendamento do dia e horário para a entrevista domiciliar.

5. No domicílio das mães cadastradas, fez-se inicialmente uma reapresentação dos objetivos da pesquisa, do instrumento de coleta de dados e orientação para a leitura do Termo de Consentimento Livre e Esclarecido (TCLE).

6. A entrevista foi realizada em um local da residência que apresentasse boa iluminação, tranquilidade e silêncio, procurando assegurar a privacidade da participante. As respostas foram anotadas em formulário próprio para posterior 
alimentação do banco de dados. Cada entrevista teve duração média de 60 minutos

\section{Instrumentos de coleta e análise dos dados}

Para avaliação dos impactos da emigração sobre a vida da mulher do emigrado foi realizada uma entrevista baseada num roteiro específico desenvolvido para este estudo. Tal roteiro buscou identificar as mudanças na vida diária, afetiva e sexual ocorridas a partir da ausência do parceiro. O roteiro norteador da entrevista continha vinte e seis questões para as quais não eram indicadas alternativas, deixando as entrevistadas livres para expressarem-se de acordo com suas vivências e expressões. As variáveis consideradas foram as seguintes: 1) idade, 2) escolaridade, 3) estado civil, 4) tempo de relacionamento, 5) tempo de isolamento conjugal, 6) motivação para emigrar, 7) reação da mulher diante da decisão da partida do parceiro, 8) providências tomadas pelo parceiro a partir da chegada no Exterior, 9) o sentimento diante das providências tomadas pelo parceiro, 10) atitudes tomadas pela mulher a partir do envio de remessas de dinheiro, 11) as atitudes tomadas pela mulher diante da falta do parceiro, 12) opções de lazer na ausência deste, 13) sentimentos diante de outros casais, 14) frequência anual de visitas médicas, 15) medicação utilizada pela entrevistada, 16) existência de prescrição médica, 17) sintomas apresentados, 18) tempo de uso do medicamento, 19) autoestima a partir da ida do parceiro, 20) sua avaliação sobre o distanciamento; 21) representação individual de casamento 22) com quem a entrevistada reside, 23) religião, 24) situação quanto à libido. 25) atitudes diante do desejo sexual, 26) percepção quanto à traição feminina.

A apuração dos dados qualitativos foi realizada segundo a técnica da Análise do Discurso (Bardin, 2009), utilizando-se fragmentos dos discursos das entrevistadas relacionados às alterações decorrentes do isolamento conjugal na vida cotidiana das mulheres de emigrados.

Os dados quantitativos foram tratados estatisticamente por meio do programa SPHINX, que, além de realizar a organização dos dados, forneceu quadros e tabelas. A análise desses quadros e tabelas, feita pela utilização do teste Qui-quadrado $\left(\chi^{2}\right)$, permitiu a verificação da existência ou não de uma interdependência entre as variáveis em observação neste estudo.

Este estudo foi submetido e ao Comitê de Ética em Pesquisa da Universidade à qual o projeto está vinculado, o qual o aprovou. Todas as participantes leram e assinaram o Termo de Consentimento Livre e Esclarecido (TCLE). O TCLE assegurava-lhes o caráter confidencial de suas respostas e seu direito de não identificação, reforçando que a pesquisa possui caráter voluntário.

\section{Resultados}

As entrevistadas têm, em média, 33 anos; 47,5\% delas contam mais de doze de relacionamento e o tempo de residência de seus parceiros no Exterior gira em torno de três anos. Em decorrência de cobranças do parceiro emigrado, ciúmes, vigilância familiar e social, $72,8 \%$ das entrevistadas desenvolvem ações que tendem a aumentar o isolamento social, gerando sentimentos de solidão.

Esse isolamento agrava as carências e adaptações relativas à separação, que poderiam ter menor impacto diante de um amparo e de uma maior integração na rede social. A solidão, a saudade e o estresse tendem a ser compensados na alimentação, nos contatos telefônicos com o cônjuge, no uso de medicamentos e nas orações. Outras $27,2 \%$ procuram relacionar-se socialmente visitando amigos e parentes, saindo para conversar com pessoas que não fazem parte do convívio familiar (Tabela 1). 
Tabela 1: Alternativas na Ausência do Parceiro

\begin{tabular}{|c|c|c|}
\hline Alternativas & Frequencia & Porcentagem \\
\hline Busco apoio na religião & 120 & 26,3 \\
\hline Mantém contato telefônico com o cônjuge & 106 & 23,2 \\
\hline Sai para se distrair e conversar & 94 & 20,6 \\
\hline Chora, se deprime ou compensa na alimentação & 75 & 16,4 \\
\hline Visita parentes e amigos & 29 & 6,5 \\
\hline Entrega-se ao trabalho & 22 & 4,8 \\
\hline Toma remédios & 10 & 2,2 \\
\hline
\end{tabular}

Fonte: pesquisa de campo

Casos válidos: 247

Mudanças significativas ocorreram no cotidiano dessas mulheres, que antes contavam com a presença diária dos parceiros em suas vidas. Muitas relatam que a distância contribuiu de forma negativa para a manutenção de seus relacionamentos, concorrendo para a separação definitiva de muitas delas.

\begin{abstract}
"Às vezes a única coisa que eu sinto dele, saudade do que nós fomos, mas bem lá atrás. Um dia ele falou comigo assim, ele falou que ia voltar, né, agora ele não vai voltar porque ele tá mexendo com a documentação, então eu acredito que ele não volte. Ele falou que ia voltar e eu falei assim: "se for voltar o cara que chegou aqui em janeiro, precisa voltar não, agora se for pra voltar o marido que foi pela primeira vez será muito bemvindo" (M., 42 anos, 5 de isolamento).
\end{abstract}

"Tem momentos que a gente se sente bastante sensibilizada... Eu, na área sexual, pra mim foi o pior, pois sou totalmente carente nessa área. Sou totalmente dependente disso, eu sou muito agitada" (S., 38 anos, 4 de isolamento)

Conforme mostra a tabela 2, 33,2\% das entrevistadas participam de atividades organizadas pela igreja. Essa instituição constitui-se num espaço de participação irrestrita das mulheres - e até mesmo indicado pela família, parceiro e sociedade - ao contrário de instituições seculares, como clubes recreativos e academias. Embora não seja propriamente um espaço de lazer, a igreja acaba sendo representada como tal. Na prática, ela torna-se um local onde encontram apoio junto a outros fiéis, o que gera algum bem-estar e energia para melhor vivenciar o distanciamento do parceiro.

Tabela 2. Opções de Lazer

\begin{tabular}{|l|r|r|}
\hline \multicolumn{1}{|c}{ Lazer } & Frequencia & Porcentagem \\
\hline Ir à igreja & 144 & 33,2 \\
\hline Assistir Tv e ler livros & 101 & 23,3 \\
\hline Ir ao shoppimg para compras e cinema & 93 & 21,4 \\
\hline Visitar parentes e amigos & 75 & 17,3 \\
\hline Praticar esporte ou academia & 21 & 4,8 \\
\hline \multicolumn{1}{|c|}{ Total } & $\mathbf{4 3 4}$ & $\mathbf{1 0 0 , 0}$ \\
\hline
\end{tabular}

Fonte: pesquisa de campo

Casos válidos: 247

As opções de lazer assumidas refletem em grande parte o nível cultural ou as aspirações das entrevistadas. Vale salientar que, seja qual for a escolha, esta deve estar de acordo com as expectativas do parceiro e das famílias envolvidas. Caso contrário, a busca da mulher por um relacionamento mais sociável ou de crescimento pessoal tende à separação como consequência. Seguem abaixo alguns fragmentos de inúmeros relatos das entrevistadas em relação ao tema.

"Parei minha vida total, parei. Teve um dia que falei: vou estudar. Já tinha feito o segundo grau há dez anos. Aí resolvi entrar pro curso de enfermagem, ai eu voltei a estudar, e foi isso que me ajudou. Onde eu chegava na faculdade eu falava que isso pra 
mim foi uma terapia, pois eu tinha parado total: não saía, ia à igreja de vez em quando, até então minha vida parou. Na faculdade eu tinha um lugar que eu podia respirar, podia conversar com outras pessoas, conviver" (J., 30 anos, 6 de isolamento).

"Mudou, porque hoje eu sou uma pessoa que não vou em lugar nenhum, não vou em festa nenhuma. Eu sinto que eu tenho que levar o meu filho pra ele ficar sociável e tudo, mas eu não vou, aqui tem a festa da cultura aqui, eu nunca fui depois que meu marido foi embora, que a vida piorou e comecei a discutir com meu marido por telefone" (D., 49 anos, 2 de isolamento).
"Não, não é porque ele proíbe, é porque acho assim. Eu gosto de festa ao lado dele, então eu prefiro não ir. Como vou chegar sozinha, eu prefiro ficar em casa. Só vou na igreja, na casa da minha mãe, da minha sogra, só" (D., 36 anos, 5 de isolamento).

A situação de isolamento contribui para que $80,9 \%$ das entrevistadas vivenciem sentimentos que tendem a desenvolver nelas uma baixa autoestima. A maior parte das entrevistadas relaciona esses aspectos negativos à ida do parceiro. Neste sentido percebemse como mais ansiosas, deprimidas, impacientes, insatisfeitas, feias entre outros atributos, desqualificando-se em termos físicos e emocionais. Isto está indicado na tabela 3 . Apenas $19,1 \%$ possuem uma autopercepção positiva.

Tabela 3: Autopercepção a Partir do Isolamento Conjugal

\begin{tabular}{|l|r|r|}
\hline \multicolumn{1}{|c|}{ Autopercepção } & Frequencia & Porcentagem \\
\hline Mais ansiosa, impaciente e irritada & 280 & 45,8 \\
\hline Mais triste, só, velha e inferior & 136 & 22,3 \\
\hline Mais feia e gorda & 78 & 12,8 \\
\hline Mais bonita e magra & 74 & 12,1 \\
\hline Mais livre, independente e feliz $\quad$ Total & $\mathbf{6 1 1}$ & $\mathbf{1 0 0 , 0}$ \\
\hline \multicolumn{1}{|c|}{ Total }
\end{tabular}

Fonte: pesquisa de campo

Casos válidos: 247

Após vivenciar e familiarizar-se com a ausência do companheiro, com novos papéis que precisam ser assumidos e com a saudade, grande parte das entrevistadas repensa o apoio oferecido por elas na partida dos parceiros como impensado e inconsequente. Embora tenham consciência das necessidades de melhoria financeira da família, 79,3\% delas acreditam que o marido e a mulher devem estar juntos nos bons e maus momentos, como mostra a tabela 4.

Tabela 4: Prioridade do relacionamento conjugal

\begin{tabular}{|l|r|r|}
\hline \multicolumn{1}{|c}{ Prioridade do relacionamento conjugal } & Frequencia & Porcentagem \\
\hline Estar juntos nos bons e maus momentos & 195 & 79,3 \\
\hline Trabalhar para um futuro melhor para os filhos & 35 & 14,2 \\
\hline Fazer de tudo para ter uma vida financeira estavel & 16 & 6,5 \\
\hline Total & $\mathbf{2 4 6}$ & $\mathbf{1 0 0 , 0}$ \\
\hline
\end{tabular}

Fonte: pesquisa de campo

Casos válidos: 246

Como assinalado por diversos autores (Fusco, 2006; Siqueira, 2006), a busca por melhores condições financeiras constitui-se na maior motivação para que homens e mulheres participem do processo emigratório. $\mathrm{O}$ desejo de partir para o Exterior é algo compartilhado pelos casais e incentivado por familiares. Efetivamente, o emigrar constitui-se num projeto familiar em que inicialmente pouco se pensa nas consequências para a vida a dois. É a partir da experiência que a mulher que assumiu com o parceiro os riscos futuros do isolamento conjugal descobre efetivamente que a escolha deveria ter sido outra, como se observa no relato abaixo.

"Graças a Deus nós tivemos outra chance e voltamos. Mas a ida para o Exterior não valeu muito não, valeu como experiência e mais nada, só sofrimento mesmo. Ficamos separados durante sete meses e nós 
resolvemos voltar" (M, 45 anos, 2,5 de isolamento).

"Olha, sinceramente essa coisa dele ter ido pra lá, eu acho isso errado, eu acho que nó... nunca ninguém tem que ir, porque quem tem família, ou vai todo mundo ou então não vai ninguém" (D, 49 anos, 2 de isolamento).

\section{DISCUSSÃO}

Conforme os resultados da pesquisa, as entrevistadas têm, em média, 12 anos de relacionamento, o que sugere a existência de toda uma dinâmica conjugal própria, arraigada no cotidiano dos casais, que veio a ser alterada pelo distanciamento. Aspectos simples, que vão desde a companhia do parceiro e a divisão de tarefas, chegando até ao amparo emocional, afetivo e sexual, passaram a ser objeto de profundas transformações.

As parceiras de emigrantes passam a responsabilizar-se por tarefas antes a eles delegadas, tais como o pagamento das contas, administração do dinheiro enviado, educação dos filhos e outras. A ausência do parceiro tende a ser uma variável que muito contribui para o baixo rendimento escolar dos filhos do casal.

Segundo Almeida e Dias (2004, p. 77), as consequências dessa separação são múltiplas, pois, "Além de a mulher não mais poder contar com o parceiro para discutirem e buscarem juntos resolver as diversas situações que afligem os membros da família no dia-a-dia, ela perde também, por longos períodos, seu parceiro sexual". Assim, com a ida do parceiro para o Exterior, a mulher que permanece em Governador Valadares passa a vivenciar restrições relativas a liberdade, sociabilidade, lazer e sexualidade.

Quanto à forma de controle da moralidade e sexualidade feminina, Assis (2002) relata que em alguns casos as mulheres que permanecem na cidade têm as remessas de dinheiro entregues pelo sogro. Tal ocorrência aumenta a dependência da mulher em relação à família do parceiro, reduzindo sua autonomia e as possibilidades de estabelecimento de relacionamentos extraconjugais.

Por estarem sós, muitas dessas mulheres sentemse desencorajadas de dar continuidade à participação em atividades sociais a que anteriormente estavam acostumadas. Em decorrência, 72,8\% desenvolvem ações que tendem a aumentar o isolamento social, como procurar alívio na alimentação, nos contatos telefônicos com o cônjuge, no uso de medicamentos e nas orações, conforme mostra a Tabela 1. Destarte, além de vivenciarem a ausência do companheiro no seu dia a dia, estas mulheres acabam por abrir mão das relações sociais, que supririam parte da carência afetiva provocada por essa ausência. O resultado é uma dupla solidão. Além da ausência do parceiro elas passam a vivenciar um quadro de isolamento em relação à rede social.

Estudos demonstram que relações sociais empobrecidas constituem-se como fator de risco à saúde que equivalem ao fumo, alta pressão arterial, a obesidade e a ausência de atividade física (Andrade \& Vaitsman, 2005). O apoio social recebido antes da ida do companheiro para o Exterior se constituía num ampliador de auxílio recíproco, uma vez que a integração das mulheres nessa rede era, em geral, mais forte e unificada.

Em relação ao apoio social, estudos relacionados à influência dos recursos psicossociais sobre a saúde afirmam que o apoio social teria efeito de tamponamento (buffer) em circunstâncias estressantes (Andrade et al., 2005). Para este modelo, o suporte social funciona como proteção, ao suavizar as consequências negativas de eventos estressantes sobre o bem-estar físico e psicológico do sujeito (Seidl \& Tróccoli 2006). Além disso, o apoio social seria responsável por exercer uma influência positiva sobre o bem-estar e a saúde geral dos indivíduos independentemente do coeficiente do estresse ou circunstâncias de tensão.

Ainda neste sentido, Baptista, Baptista e Torres (2006, p. 40) apontam para evidências de que o "suporte social seja responsável pela redução de impacto de diversos transtornos psiquiátricos/psicológicos, tais como a depressão, transtornos ansiosos e esquizofrenia e, podem também estarem associados ao desenvolvimento e tratamento e prognóstico desses problemas".

Quanto ao apoio social que as redes possibilitam, enfatizam-se aqui os aspectos positivos das relações sociais. Entre eles vale destacar: a troca de informações úteis; o auxílio emocional e prático oferecido pelos amigos em momentos de crise, de saudades do companheiro; a presença em eventos sociais, como aniversários, ou mesmo a simples presença de pessoas conhecidas em momentos triviais como compras em supermercados e outros. Por mais que atividades rotineiras sejam rudimentares, estas se constituem como possibilidade de entrosamento e participação social, quando realizadas em companhia de outros indivíduos da comunidade. Toda essa gama de atividades, que outrora era vivenciada em maior 
dimensão, frequência e profundidade, após a ida do parceiro sofre sensível embotamento, que caracteriza o isolamento social.

O envolvimento na comunidade, que poderia constituir-se como elemento psicossocial relevante no aumento da autoconfiança, da autoestima, da saúde física e emocional, da satisfação com a vida e da capacidade de enfrentar problemas, é, na verdade, evitado. Estudos comprovam que quadros de enfermidades podem ser amenizados segundo a disponibilidade do apoio social oferecido. As redes de apoio e o convívio social influenciam diretamente a vontade de viver e a autoestima dos pacientes, contribuindo para o sucesso do tratamento (Minkler, 1985 citado por Andrade \& Vaitsman, 2005).

$\mathrm{O}$ isolamento social pode ser definido como uma experiência de privação socioemocional em relação não somente à vida conjugal e sexual, mas também à rede social. Esse isolamento se dá em nome do apoio afetivo do companheiro que se encontra fisicamente distante. Tal isolamento caracteriza-se pelo declínio da dimensão e profundidade de vínculos estabelecidos nas redes sociais e pela diminuição da amplitude da natureza (vizinhas, amigas de infância, colegas de atividades esportivas, etc.) e da qualidade e frequência dos contatos. Na maioria dos casos, amigos e conhecidos da mulher do emigrado saem de cena. Os familiares tornam-se foco de suas atenções, não tendo mais com quem compartilhar suas insatisfações sem que seja repreendida ou motivo de espanto.

$\mathrm{O}$ grau de intimidade anteriormente compartilhado com outros membros da rede e o envolvimento social com estes acabam defasados. As redes aqui referidas têm o sentido de pontos ou indivíduos conectados por fios relacionais de forma a compor a figura de uma rede de pesca. Quando as entrevistadas encontravam-se ligadas às suas redes de relações, elas automaticamente conectavam-se a outras pessoas, numa relação de interdependência e policentrismo (Oliveira, 2002 citado por Andrade \& Vaitsman, 2005). Além disso, a perda de contato com apenas um membro, um ponto da rede, implica na perda de contato que ele viabilizava com pelo menos um terceiro, dependente do elo do segundo com o primeiro.

Entre as diferentes ideias englobadas no conceito de rede social está também a ideia de "teia", proposta por Bowling (1997). Segundo o autor, as relações sociais que circundam o indivíduo possuem tanto as características explicitadas anteriormente (disponibilidade, frequência e qualidade dos contatos com amigos, parentes e conhecidos) quanto os contatos ou alguma forma de participação social por meio de grupos de pessoas (grupos religiosos, que são as opções mais procuradas de lazer, além de associações de bairro, de sindicatos ou das instituições de ensino onde seu(s) filho(s) encontra(m)-se matriculado(s).

Existe ainda mais um aspecto que deve ser levado em consideração na análise da sociabilidade. Para Bowling (1997, citados por Chor, Griep, Lopes \& Faerstein, 2001), o grau em que relações interpessoais correspondem a determinadas funções (apoio emocional, material e afetivo) está intimamente ligado ao grau de contentamento do indivíduo com a disponibilidade e qualidade dessas funções. Cobb (1976, citado por Chor; Griep Lopes \& Faerstein, 2001) caracteriza apoio social como um vínculo que faz com que o indivíduo se sinta querido, amado e valorizado. Esse vínculo este leva o sujeito a se sentir como parte do todo de uma rede social com a qual estabeleceu compromissos mútuos e ações recíprocas. Este sentimento produz efeitos positivos tanto para quem recebe como para quem oferece o apoio.

Embora os mecanismos de ação exercidos pela rede e apoio social nos sistemas de defesa do organismo humano e na sua saúde psíquica e física ainda não tenham sido completamente elucidados, existem estudos significativos sobre o assunto. Nesses estudos é levantada a hipótese de que a sociabilidade atuaria "tamponando" a resposta do organismo em forma de doença, que pode ocorrer em consequência de grandes perdas ou rupturas emocionais de acordo com o que foi apontado por Chor et al. (2001).

Assim, a ida do parceiro e as mudanças inevitáveis envolvidas neste processo seriam sensivelmente atenuadas diante de vínculos sociais de qualidade, que, em geral, não são estabelecidos. $O$ recrudescimento da falta de sociabilidade vivenciado pelas mulheres de emigrados engendra um círculo vicioso que tende a desintegrar sua inserção nas redes sociais. Tais processos costumam ser potencializados e a desvitalização dos laços sociais acaba por ocasionar uma baixa autoestima, muitas vezes relacionada à depressão. A depressão, por sua vez, estabelece quadros de apatia e desinteresse que acabam por desvitalizar ainda mais as relações pessoais (Teles, 1992).

A união destes fatores culmina na diminuição do bem-estar psicológico e na insatisfação com a vida em geral. A rede de relações sociais, que se constituiria como importante moderador da experiência de isolamento social, é evitada. A mulher se torna "presa da solidão, embora às vezes se encontre em uma família numerosa" (Morgado, 1986, p. 82). Essa 
solidão, na maioria dos casos, degrada tanto a saúde física quanto a psíquica da mulher do emigrado.

A relação entre laços sociais e saúde foi sugerida por Cassel (1974), quando buscava indicativos de um paralelo entre a ruptura de laços sociais e a vulnerabilidade a doenças. Neste sentido, Chor et al. (2001, p. 888) fazem a seguinte observação:

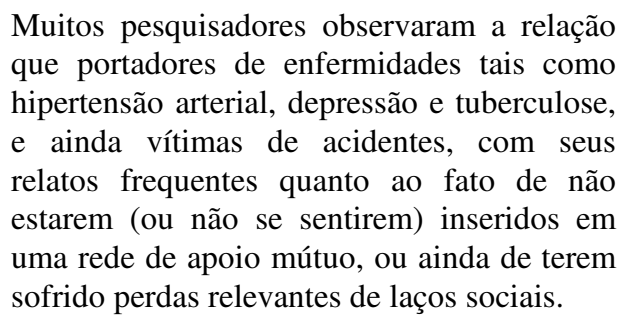

Tais estudos deixam em evidência que a solidão, a perda da presença constante e rotineira do companheiro, fatores estressores e novos em seu cotidiano, somados ao abandono de sua vida social, põem em risco sua saúde psíquica e física. A depressão é um elemento presente no discurso das entrevistadas, tanto daquelas que tomam algum medicamento quanto daquelas que não o fazem. Teles (1992, p. 54) define depressão como “[...] um sintoma que faz parte de diversos distúrbios e síndromes, tendo seu curso e prevalência variáveis, pode apresentar ou não, sintomas somáticos e ainda pode ser classificada como uma doença assinalada por graves alterações afetivas".

Compartilhando o mesmo ponto de vista dos autores citados, Resende, Bones, Souza e Guimarães (2006) afirmam que "as pessoas que apresentam maior satisfação para com a vida hoje são aquelas que recebem mais suporte afetivo, que contam com outras para suporte instrumental acreditam que estarão mais satisfeitas no futuro".

A hipótese da inter-relação entre o isolamento social vivenciado pelas mulheres de emigrados e a constatável debilidade de sua saúde emocional é corroborada pela análise dos dados, em que se verificou uma sensível mudança na autoestima, na autoimagem, na saúde emocional e até mesmo física das entrevistadas. O embotamento da saúde emocional pode resultar de relações complexas entre o fator situacional, correspondente à ida do parceiro para o Exterior, e o fator social, que implica em geral o enfraquecimento da sociabilidade. Essa associação acaba por gerar uma variável psicológica negativa que, em alguns casos, culmina em quadros depressivos.

\section{CONCLUSÃO}

$\mathrm{O}$ isolamento social e o enfraquecimento das redes relacionais fazem parte do cotidiano das mulheres de emigrados. Esse isolamento é resultado de variáveis como ciúmes do parceiro, vigilância familiar, especulação social e tentativa de controle da moral feminina, as quais que incutem na mulher a sensação constante de estar sendo fiscalizada e inspecionada, sensação que a aprisiona na redoma da solidão, onde a tristeza é companhia constante.

Mudanças como a sobrecarga de responsabilidades, a angústia da distância, as saudades, a sexualidade não vivenciada, a sensação relatada de que "quando ele viaja não sinto que tô casada, mesmo sem pôr o pé na rua. Casamento é casal junto", e a incerteza quanto a um retorno muitas vezes prorrogado, são, por si próprios, aspectos negativos do distanciamento em relação ao parceiro, distanciamento qie provocado pela participação deste no processo emigratório. Esses aspectos poderiam ser contornados e amenizados na presença de uma rede de apoio social estruturada dirigida a essas mulheres, seus filhos e outras pessoas envolvidas direta ou indiretamente com o projeto de emigração. Tal rede de apoio poderia contribuir para que esse processo fosse vivenciado de forma sadia, o que raramente ocorre: pelo contrário, constata-se que a partir da ida do parceiro para o Exterior o isolamento é variável presente, constituindo-se como elemento-chave que desencadeia toda uma série de consequências físicas e psicológicas negativas, observadas em $71,6 \%$ dos casos estudados.

$\mathrm{O}$ isolamento social vivenciado pela mulher do emigrado não é uma opção, mas um efeito colateral da escolha por uma solução para dificuldades financeiras enfrentadas pela família. É um efeito colateral por ser uma consequência negativa resultante de uma opção de distanciamento que, em princípio. seria a solução para os problemas do casal.

\section{REFERÊNCIAS}

Almeida, A. \& Dias, C. A. (2004). Dificuldades afetivas e sociais vivenciadas pela mulher cujo cônjuge reside no exterior como emigrante. Revista Brasileira de Sexualidade Humana, 15(2), 73-91.

Andrade, C. R., Chor, D., Faerstein, E., Griep, R. H., Lopes, C. S. \& Fonseca, M. J. M. (2005). Apoio social e autoexame das mamas no Estudo Pró-Saúde. Cadernos de Saúde Pública, 2(21), 379-386.

Andrade, G. R. B. \& Vaitsman, J. (2005). Apoio social e redes: conectando solidariedade e saúde. Ciência e saúde coletiva, 4(7), 925-934. 
Assis, G. (2002). Estar Aqui, Estar Lá... uma cartografia da vida entre o Brasil e os Estados Unidos. Campinas: Núcleo de Estudos de População/UNICAMP.

Assis, G. (2007). De Governador Valadares e Criciúma para Boston. Nuevo Mundo Mundos Nuevos, 7. Recuperado em 20 dezembro, 2007, de http://nuevomundo.revues.org/document3754.html.

Babbie, E. (2005). Métodos de Pesquisas de Survey. Belo Horizonte: Editora UFMG.

Baptista, M. N., Baptista, A. S. D. \& Torres E. C. R. (2006). Associação entre suporte social, depressão e ansiedade em gestantes. PSIC - Revista de Psicologia da Vetor Editora, 1(7), 39-48.

Bardin, L. (2009). Análise de Conteúdo. Coimbra: Edições 70.

Bowling, A. (1997). Measuring social networks and social support. In: Measuring Health: a Review of Quality of Life Measurements Scales, 1(2), 91-109. Baltimore: Open University Press.

Cassel, J. C. (1974). An epidemiological perspective of psychosocial factors in disease etiology. American Journal of Medicine, 11(64), 1040-1043. Recuperado em 03 março, 2008, de http://www.ajph.org/cgi/content/citation/64/11/1040 .

Chor, D., Griep, R. H. Lopes, C. S. \& Faerstein E. (2001). Medidas de rede e apoio social no Estudo Pró-Saúde: prétestes e estudo piloto. Cadernos de saúde pública, 4(6), 887-896.

Fusco, W. (2001). Diferenciais por Sexo nas Migrações Internacionais. Anais do Encontro Nacional de Estudos Populacionais, 12. Caxambu, MG, Abep.

Fusco, W. (2006). Conexão origem-destino: migrantes brasileiros no exterior. Anais do Encontro Nacional de Estudos Populacionais, 15 (pp.1-17). Caxambu, MG, Abep.

IBGE. (2007). Situação Demográfica: População estimada. Recuperado em 15 junho, 2010 de http://www.ibge.gov.br/seculoxx/arquivos_pdf/populacao /1969/populacao_m_1969aeb_007.pdf.

Machado, I. \& Reis, E. (2007). Algumas conclusões a cerca do fluxo de valadarenses para Portugal. Teoria e pesquisa, 1(16), 153-166.
Morgado, B. (1986). A solidão da mulher bem casada. Rio de Janeiro: José Olimpio.

Norbeck, J. S., Lindsey, A. M. \& Carrieri V. L. (1981). The development of an instrument to measure social support. Nursing Research, 5(30), 264-269. Recuperado em 3 agosto, $2008 \mathrm{de}$ http://www.ncbi.nlm.nih.gov/sites/entrez?db=pubmed\&ui $\mathrm{d}=7027185 \& \mathrm{cmd}=$ showdetailview $\&$ indexed $=$ google.

Oliveira, A. C. (2002). A Emigração de Brasileiros para os Estados Unidos - o caso de Miami. Anais do Encontro de Estudos Populacionais da ABEP, 13. Ouro Preto, MG, Abepl.

Resende, M. C., Bones, V. M., Souza, \& Guimarães, N. K. (2006). Rede de relações sociais e satisfação com a vida de adultos e idosos.Psicologia para América Latina. Recuperado em 01 dezembro, 2009 em: $<\mathrm{http}: / /$ pepsic.bvspsi.org.br/scielo.php?script=sci_arttext\&pid=S1870350X2006000100015\&lng=pt\&nrm=iso $>$.

Seidl, E. M. F. \& Tróccoli, B. T. (2006). Desenvolvimento de escala para avaliação do suporte social em HIV/aids. Psicologia: Teoria e Pesquisa, 3(22), 317-326

Siqueira, S. (2004) Migrantes e empreendedorismo na microrregião Governador Valadares - Sonhos e frustrações no retorno. Tese de doutorado. Faculdade de Filosofia e Ciências Humanas, UFMG, Belo Horizonte, MG.

Siqueira, S. (2006). Emigrantes da Microrregião de Governador Valadares nos EUA: Projeto de retorno e investimento. Anais do Encontro Nacional de Estudos Populacionais, 15, Caxambu, MG.

Teles, M. L. S. (1992). O que é depressão. São Paulo: Brasiliense.
Endereço para correspondência:
Clarisse Sousa Boechat. Campus Antônio Rodrigues Coelho. Rua Israel Pinheiro, 2000, Bairro Universitário, Cx. Postal 295, CEP 35020-220, Governador Valadares-MG, Brasil. E-mail: clarisse.boechat@gmail.com. 